\title{
Isolation of the LEMMI9 Gene and Promoter Analysis During a Compatible Plant-Nematode Interaction
}

\author{
Carolina Escobar, ${ }^{1}$ Jan De Meutter, ${ }^{2}$ Fabio A. Aristizábal, ${ }^{1,4}$ Soledad Sanz-Alférez, ${ }^{1}$ \\ Francisca F. del Campo, ${ }^{1}$ Nathalie Barthels, ${ }^{2}$ Walter Van der Eycken, ${ }^{2}$ Jef Seurinck, ${ }^{5}$ \\ Marc van Montagu, ${ }^{2}$ Godelieve Gheysen, ${ }^{2,3}$ and Carmen Fenoll ${ }^{1}$ \\ ${ }^{1}$ Departamento de Biología, Universidad Autónoma de Madrid, Cantoblanco, 28049 Madrid, Spain; \\ ${ }^{2}$ Laboratorium voor Genetica, Department of Genetics, VIB, Universiteit Gent, K.L. Ledeganckstraat 35, \\ B-9000 Gent, Belgium; ${ }^{3}$ Vakgroep Plantaardige Productie, Faculteit Landbouwkundige en Toegepaste \\ Biologishe Wetenschappen, Universiteit Gent, Coupure links 653, B-9000 Gent, Belgium; ${ }^{4}$ Laboratorio \\ de Bioquímica y Biología Molecular, CIF. Santa Fe de Bogotá, Colombia; ${ }^{5}$ Plant Genetic Systems n.v., \\ Jozef Plateaustraat 22, B-9000 Gent, Belgium \\ Accepted 30 January 1999.
}

\begin{abstract}
Plant-endoparasitic root-knot nematodes feed on specialized giant cells that they induce in the vascular cylinder of susceptible plants. Although it has been established that a number of plant genes change their expression pattern during giant cell differentiation, virtually no data are available about the mechanisms involved in that change. One possibility is differential promoter recognition by the transcription factor(s) responsible for the expression of specific genes. We have isolated and characterized a genomic clone from tomato containing the promoter region of LEMMI9, one of the few plant genes that have been reported to be highly expressed in galls (predominantly in giant cells). The analysis of transgenic potato plants carrying a $L E M M I 9$ promoter- $\beta$ glucuronidase $(G U S)$ fusion has demonstrated that the tomato promoter was activated in Meloidogyne incognita-induced galls in a heterologous system. We have located putative regulatory sequences in the promoter and have found that nuclear proteins from the galls formed specific DNA-protein complexes with the proximal region of the LEMMI9 promoter. The nuclear protein-binding sequence mapped to a region of $111 \mathrm{bp}$ immediately upstream from the TATA box. This region contains a 12-bp repeat possibly involved in the formation of DNA-protein complexes, which might be related to the LEMMI9 transcriptional activation in the giant cells.
\end{abstract}

Additional keywords: DNA-binding protein(s), promoter elements.

Root-knot nematodes are sedentary endoparasites that penetrate the roots; in susceptible hosts, they establish a permanent feeding site in the vascular cylinder (Sasser and Carter

Corresponding author: Carmen Fenoll; Telephone: 34-91-397 8198; Fax: 34-91-397 8344; E-mail: Carmen.Fenoll@uam.es

Present address of Carolina Escobar: Facultad de Ciencias del Medio Ambiente, Universidad de Castilla-La Mancha, E-45071 Toledo, Spain.

Nucleotide sequence is to be found at the GenBank/EMBL DDBJ data base as accession number Z69032.
1985). Successful infections depend on the ability of the parasite (i) to remain undetected by the surveillance systems of the plant, which is in part accomplished by minimizing host damage during invasion and development, and (ii) to continuously drain nutrients from living plant cells that are altered very early by the nematode into a special type of transfer cells called giant cells. In most hosts, the cells surrounding the feeding site undergo extensive proliferation, producing a gall or knot in the root, often used to diagnose infection. Galls contain the giant cells and the nematode, as well as altered root tissues such as a hypertrophied vasculature and a swollen cortex.

Giant cells have several features that make them unique (Huang 1985). The cells initially chosen to become giant cells are first induced to undergo repeated mitoses uncoupled from cytokinesis, thus becoming multinucleated. These multiple nuclei also undergo a series of endoreduplication cycles, further increasing the ploidy level. These polyploid cells greatly increase their size and go through a series of ultrastructural and metabolic changes that, it has been proposed, help specialize the giant cells in the transfer of food resources to the nematode (Jones 1981). The molecular basis of such alterations and the mechanisms used by the nematode to trigger and maintain them are still unknown, although normal cell differentiation processes are probably involved, perhaps in a modified arrangement. It seems obvious that giant cell differentiation should involve changes in gene expression, but this has only recently received experimental support. Several laboratories have documented changes in the expression of specific genes in nematode feeding sites (reviewed by Sijmons 1993; Sijmons et al. 1994; Gheysen et al. 1996; Fenoll et al. 1997). In the cases in which it has been tested, gene expression changes in giant cells occur certainly (Goddijn et al. 1993; Opperman et al. 1994; Barthels et al. 1997) or probably (Bird and Wilson 1994; Gurr et al. 1991; Van der Eycken et al. 1996) at the level of promoter activation. These findings suggest that nematodes induce changes in the activity of plant transcription factors that are possibly part of the differentiation mechanisms that control giant cell formation. Therefore, detailed analysis of nematode-responsive promoters and iden- 
tification of the particular transcription factors (of plant or nematode origin) that are responsible for the activation of such promoters in galls are a step toward understanding the cascade of molecular events linking the expression of specific genes with the unknown nematode trigger that causes giantcell differentiation.

Some of the plant genes specifically induced after nematode infection in roots have been identified as cDNA copies of abundant mRNAs in infected roots. This is the case for the tomato gene $L E M M I 9$, expressed at a basal level throughout the plant but highly transcribed in giant cells after Meloidogyne incognita infection (Van der Eycken et al. 1996). The putative protein encoded by the cDNA clone shares high homology with LEA14, a hydrophilic cotton protein belonging to the late embryogenesis abundant (LEA) class of proteins that accumulate both during embryogenesis and in vegetative tissues under water stress (Dure 1993), and whose function has been proposed to be ion sequestering during water deficit (Espelund et al. 1992; Galau et al. 1993). A similar function has not been demonstrated for LEMMI9, but its accumulation in giant cells might be related to osmotic changes during the development and functioning of these cells. Although such changes in osmolarity have not been actually measured in giant cells, four genes related to water status are also induced in galls by root-knot nematodes: the tobacco TobRB7 (Opperman et al. 1994), which encodes a putative aquaporin; the tomato TSW12 (Fenoll et al. 1997) and TAS14 (this paper), coding for a putative lipid transfer protein and a putative dehydrin, respectively (Godoy et al. 1990); and the sunflower sHSP17.7 G4 (Fenoll et al. 1997), which codes for a small heat shock protein (Coca et al. 1996).

In this work, we report the cloning and sequencing of the tomato LEMMI9. We have demonstrated its nematodeassociated inducibility in a heterologous system (transgenic potato plants) and we have located the putative transcription consensus sequences in the promoter region. To define sequence elements that are responsible for the nematodeassociated expression of LEMMI9 and to find the transcription factors that interact with them, we report the presence in the proximal promoter region of an element that interacts with nuclear proteins from galls and that might be related to the transcriptional activation of LEMMI9 in these particular root structures.

\section{RESULTS}

\section{Isolation and analysis of a genomic clone} that corresponds to the LEMMI9 cDNA.

Due to the apparent specific accumulation of LEMMI9 transcripts in tomato giant cells (Van der Eycken et al. 1996), we decided to isolate the corresponding gene, with the aim of studying its promoter. For that purpose, a tomato genomic library from the root-knot nematode resistant cv. VFNT Cherry was used. Because the original cDNA clone had been isolated from a nematode-susceptible tomato cultivar, the presence and structure of the LEMMI9 gene in the cv. VFNT Cherry genome was first confirmed by Southern hybridization. LEMMI9 appears to be a single-copy gene (data not shown). Screening of $3 \times 10^{5}$ PFU of the tomato cv. VFNT Cherry genomic library with the LEMMI9 cDNA probe yielded five positive plaques, which were further purified in two additional screening rounds. Restriction analysis revealed that the clones were overlapping and corresponded to the same gene. A 3.5$\mathrm{kb}$ EcoRI genomic fragment that hybridized with $5^{\prime}$-specific probes but not with $3^{\prime}$-specific probes from the cDNA was subcloned in pUC19. A restriction map of this $3.5-\mathrm{kb}$ clone was made, and $2.8 \mathrm{~kb}$ were sequenced. Sequence comparison showed no mismatches between the exons and the cDNA sequence. A putative TATA box and the derived exon 1 protein sequence were identified. The position of the intron was determined by alignment of the genomic (accession number Z69032) and the cDNA sequences (Van der Eycken et al. 1996).

\section{LEMMI9 promoter activation in transgenic potato lines.}

The expression pattern of the LEMMI9 promoter was analyzed in transgenic potato plants carrying the 1,414-bp sequence immediately upstream from the ATG in the LEMMI9 genomic sequence fused to the $\beta$-glucuronidase $(G U S)$ reporter gene (see Materials and Methods). A total of 24 transgenic lines were obtained, of which five showed a GUS expression pattern comparable to that defined by accumulation of the LEMMI9 gene transcripts in tomato (Van der Eycken et al. 1996). GUS expression in feeding sites was clearly visible 1 week after nematode infection (Fig. 1A). The expression was maximal around 3 to 4 weeks post inoculation and then gradually decreased. The staining pattern remained roughly the same during the whole infection period: the promoter was preferentially activated in giant cells (Fig. 1B), but low levels of expression were also detected in the surrounding vascular tissue and sometimes around the nematode body (Fig. 1C). In the aerial part of the plants, vascular tissue and axillary buds also showed GUS expression (Fig. 1D).

\section{The $L E M M I 9$ promoter specifically interacts with proteins from root galls.}

The strong activation of the tomato LEMMI9 promoter in giant cells in a heterologous system (potato) indicated its possible use to engineer nematode resistance through expression of anti-nematode or cytotoxic proteins. However, since expression was not absolutely restricted to giant cells, further analysis of the LEMMI9 promoter is needed to narrow down the putative region responsible for the expression specifically in giant cells. If particular sequences are shown to be associated with the binding of specific nuclear proteins, it is possible that such proteins might be the transcription factors that activate the LEMMI9 promoter in giant cells. Their target DNA sequences would then be the cis elements that enable the promoter to be active in giant cells.

We identified several putative cis elements in the 200-bp XhoI-HinfI fragment from the proximal region of the LEMMI9 promoter (Fig. 2) that have been described to drive gene expression in other plant promoters (see Discussion). Therefore, as a starting point for the dissection of the LEMMI9 promoter, we used this fragment to detect nuclear plant proteins that may interact with this region. Since high LEMMI9 expression in tomato roots was detected in the giant cells of the galls (Van der Eycken et al. 1996), and giant cell isolation for these biochemical assays was unfeasible, whole root galls were used to prepare a crude nuclear protein extract. Increasing amounts of protein extract were incubated with the ${ }^{32} \mathrm{P}$ endlabeled probe in the presence of $1 \mu \mathrm{g}$ of poly ( $\mathrm{dI}-\mathrm{dC})$ as com- 
petitor DNA to reduce non-specific protein binding, and the reaction mixtures were studied in an electrophoretic mobilityshift assay (EMSA). In this assay, probe migration was retarded by nuclear extracts from fully developed galls induced by $M$. incognita, indicating the presence of protein(s) that interact with the DNA fragment (Fig. 3A, lanes 5 to 7). No retardation complexes were detectable with extracts obtained from control uninfected roots with the same amount of protein (Fig. 3A, lanes 2 to 4 ). The DNA-binding activity was undetectable at early infection stages. It became apparent around 2 weeks after infection and was maintained until completion of the nematode development, about 6 weeks after infection (data not shown). That was consistent with the temporal expression pattern of both LEMMI9 transcripts in tomato inferred from "in situ" analysis (Van der Eycken et al. 1996) and GUS activity in transgenic potatoes during nematode infection.
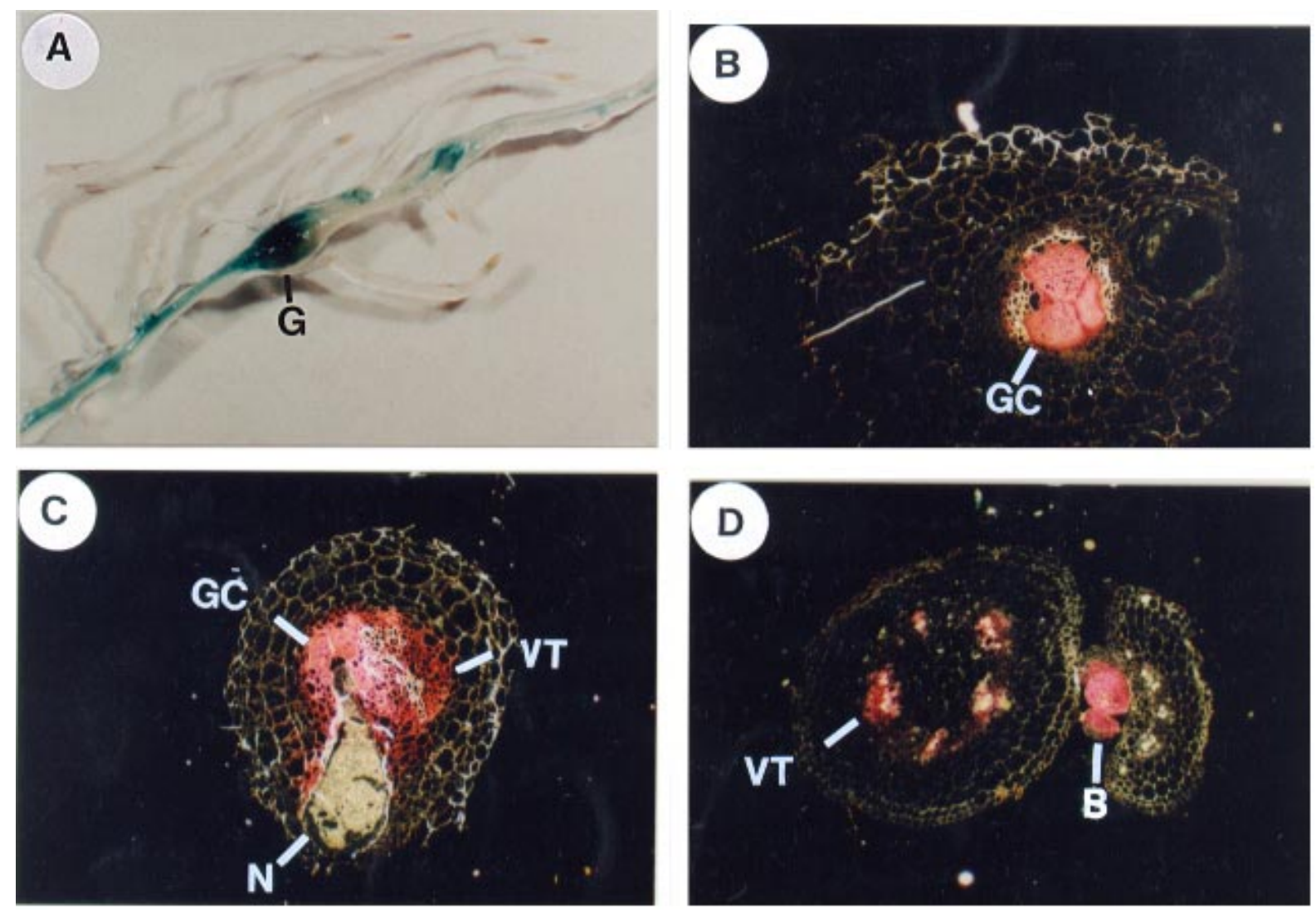

Fig. 1. Expression pattern of the $L E M M I 9$ promoter in transgenic potato plants. Histochemical staining for $\beta$-glucuronidase (GUS) activity in several transgenic potato lines carrying the LEMMI9 promoter fused to the GUS gene. GUS staining is (A) blue and (B-D) pink. A, Infected root, 7 days after infection. B and C, Root sections 4 weeks after infection. D, Section in the shoot tip area. G, galls; GC, giant cells; N, nematode; B, axillary bud; VT, vascular tissue.

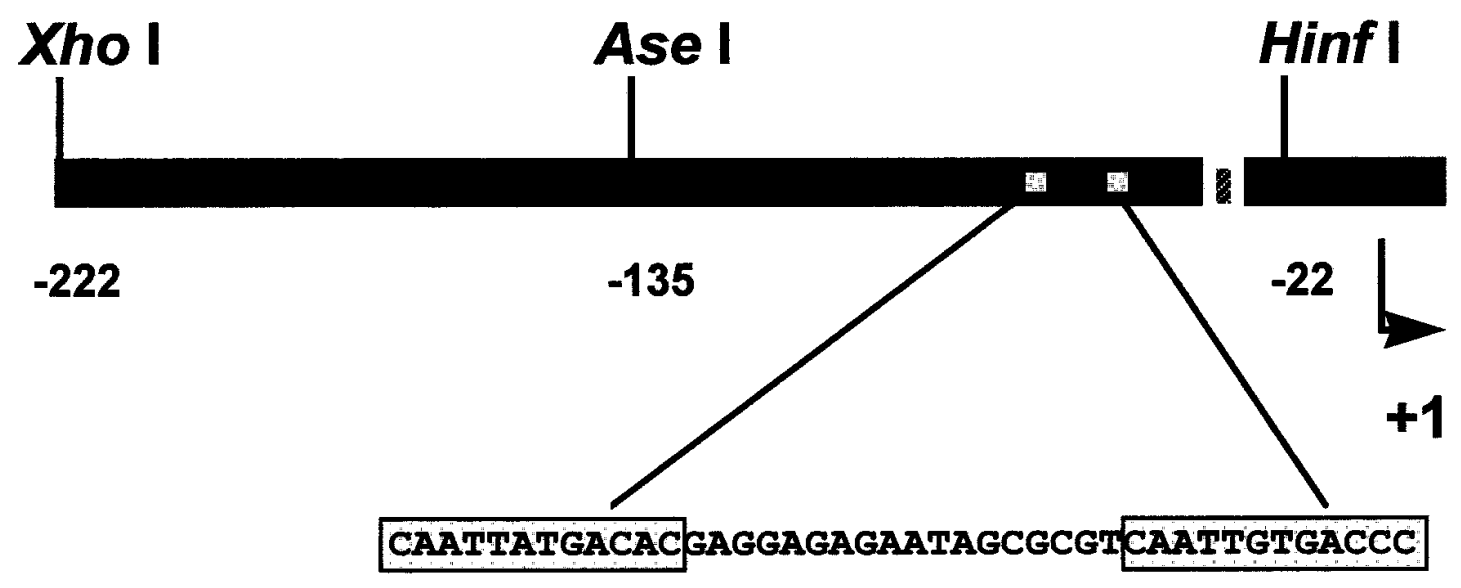

Fig. 2. Diagram of the LEMMI9 promoter. Positions of the putative TATA box (cross-lined box) and the restriction sites that flank the fragment tested for protein binding are shown. Numbers are relative to the transcription start point $(+1)$. Dotted boxes represent the imperfect 12-bp repeat, from which the sequence is shown in the blow-up. 


\section{Non-infectedM.incognita}

A

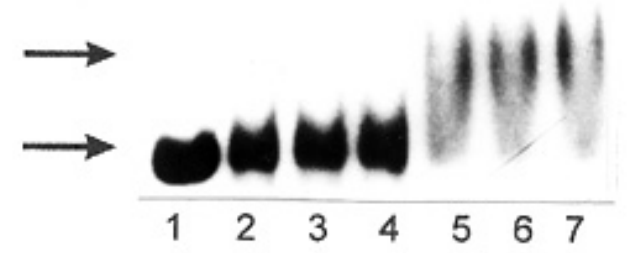

$\begin{array}{llllll}\mu \mathrm{g} \text { poly }(\mathrm{dl}-\mathrm{dC}) & 0 & 1 & 2 & 3 & 6\end{array}$

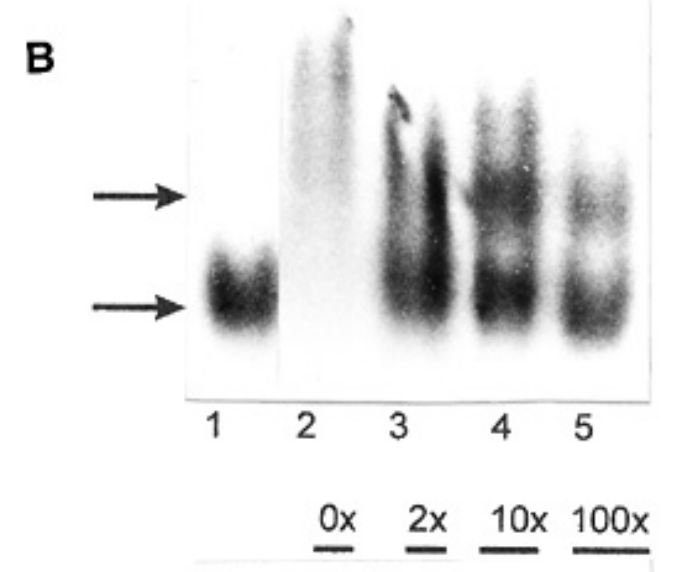

C

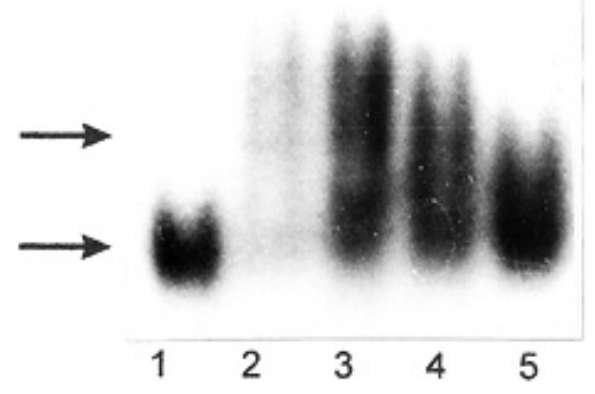

Fig. 3. Interaction of the LEMMI9 promoter with nuclear protein extracts from tomato galls. Electrophoretic mobility-shift assays (EMSAs) were performed from protein extracts from non-infected roots or from galls 20 days after inoculation with Meloidogyne incognita, incubated with $3 \mathrm{fmol}(3,000 \mathrm{cpm})$ of the XhoI-HinfI probe in the presence of $1 \mu \mathrm{g}$ of poly (dI-dC), and electrophoresed in a native polyacrylamide gel. The positions after migration of the free probe (lower bands) and the DNAprotein complexes (retarded bands) are marked by arrows. A, Lane 1: no protein extract. Amount of nuclear extract as total protein in the different reactions: lanes 2 and 5, $15 \mu \mathrm{g}$; lane 6, $20 \mu \mathrm{g}$; lanes 3 and 7, 25 $\mu \mathrm{g}$; lane 4, $35 \mu \mathrm{g}$. B, Specificity of DNA-protein complexes was tested by increasing the concentration of non-specific competitor poly (dI-dC; 1 , 2, 3, $6 \mu \mathrm{g}$ ): $40 \mu \mathrm{g}$ of total protein was used in all lanes except lane 1 (no protein extract). C, Specificity of DNA-protein complexes was tested by increasing the concentration of unlabeled probe (two-, 10-, 100-fold molar excess over the labeled probe). Lane 1, no protein extract.
To rule out that the observed retarded bands represented non-specific DNA-protein interactions with abundant but lowaffinity nuclear proteins, we tested the effect of increasing concentrations of the non-specific competitor. Figure 3B shows that, at the highest protein concentrations used (see Discussion for further explanation) most of the labeled probe was retarded into a thick smear (lanes 2 and 3). However, the smear turned into a clear retarded band when non-specific competitor was added in a high excess (Fig. 3B, lanes 4 and $5)$. The highest concentration of poly ( $\mathrm{dI}-\mathrm{dC})$ used, representing a 5,000-fold molar excess of double-stranded DNA over the DNA probe, was not enough to abolish protein binding to the LEMMI9 promoter fragment. This suggested that the retarded band observed was due to a specific interaction. To confirm the specificity of the binding, the unlabeled DNA fragment was used to compete with the labeled probe. Figure 3C shows that a 10 -fold molar excess of unlabeled competitor DNA (lane 4) was sufficient to diminish the retarded band, and a 100-fold excess (lane 5) totally abolished it. Taken together, these results strongly suggest that one or more proteins in the crude nuclear extract recognize and bind to a specific sequence in the 200-bp fragment from the LEMMI9 promoter.

\section{Salt stress only induces $L E M M I 9$ gene expression slightly in stems.}

Since the LEMMI9 protein shares high homology with osmoprotectant proteins, it might be that the nematoderesponsiveness of the LEMMI9 promoter was related to a change in the osmotic pressure in the giant cells, and that such change might be the trigger for LEMMI9 gene induction. To test this possibility, the LEMMI9 transcript levels were examined in plants subjected to high salt stress. Northern (RNA) hybridization of the LEMMI9 cDNA against mRNA from tomato plants grown in hydroponic culture with high salt concentration (Fig. 4A) showed only a slight increase in LEMMI9 mRNA levels, compared with the increase observed in the TAS14 mRNA in the same RNA samples (Fig. 4B). TAS14 is induced in tomato upon osmotic stress or ABA treatment, as well as in galls of untreated plants (Fig. 4B), and shares expression and sequence characteristics with group 2 LEA proteins (Godoy et al. 1990, 1994). The similarity of the putative LEMMI9 protein with LEA14, previously reported as $62 \%$, turned out to be even higher $(63 \%)$ after a sequence correction of the LEA 14 gene sequence (accession number Z46654). LEMMI9 seemed not to be induced by salt stress at levels comparable to those reached in galls. Consistent with this result, several transgenic potato lines showed only a moderate increase in GUS expression upon $\mathrm{NaCl}$ treatment (Fig. 4C). In addition, EMSAs performed at 50, 100, 150, and $230 \mathrm{mM}$ $\mathrm{NaCl}$ did not reveal any influence of $\mathrm{NaCl}$ concentration in DNA-protein complex formation (data not shown). These data are in accordance with the results obtained from control tomato plants and transgenic potato plants treated with $\mathrm{NaCl}$.

The DNA-binding factor is also present in nuclear protein extracts from root tips and leaves of non-infected plants.

Northern experiments by Van der Eycken et al. (1996) revealed basal accumulation of LEMMI9 transcripts in roots, leaves, stems, and fruits from infected and non-infected tomato plants. Therefore, the DNA-binding protein(s) found in 
galls might also be present at lower concentration or with lower DNA-binding activity in those tissues.

When compared with those of infected plants, equivalent amounts of protein from crude nuclear extracts of noninfected roots (see Figure 3A) or leaves (data not shown) did not produce any retarded band. Only when the protein concentration in the assay was four- to fivefold that of gall extracts could a faint retarded band that migrated at the same position be detected (data not shown). We used nucleienriched fractions (see Materials and Methods) to prepare protein extracts from leaves or uninfected roots. Such extracts are likely to have an increased ratio of nuclear to total proteins, thus improving the signal to noise ratio in the EMSAs. EMSAs performed with the nuclei-enriched extracts from root tips and leaves of non-infected tomato plants resulted in the formation of DNA-protein complexes (Fig. 5). As previously

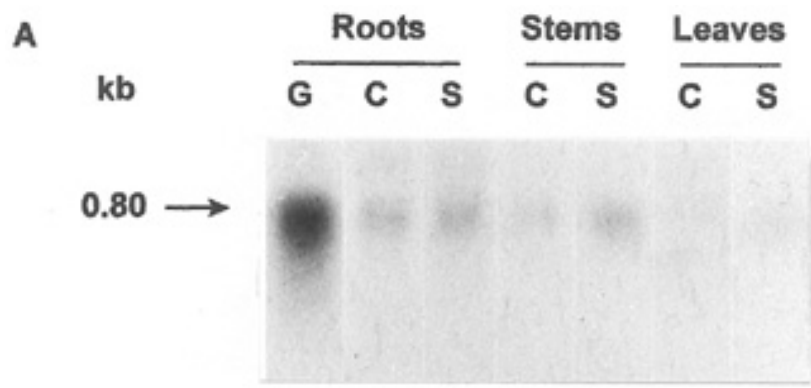

B

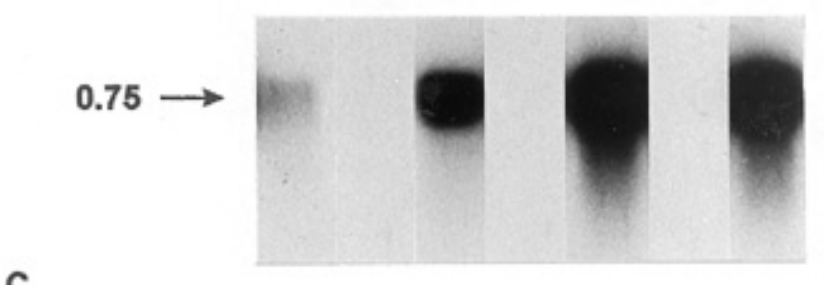

C

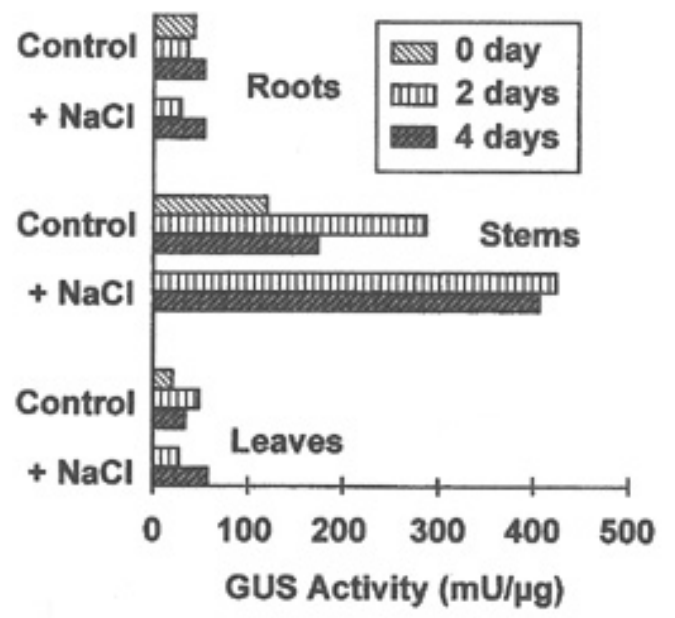

Fig. 4. Effect of salt concentration on LEMMI9 transcript accumulation and on nuclear protein binding in the $L E M M I 9$ promoter. $\mathbf{A}$ and $\mathbf{B}$, RNA gel blot analysis of LEMMI9 transcripts. Lycopersicon esculentum cv. Marmande plants were subjected to $171 \mathrm{mM} \mathrm{NaCl}$. Transcript levels of (A) LEMMI9 and (B) TAS14 genes were assessed in treated and control plants. G, galls; C, control plants; S, after 2 days in $171 \mathrm{mM} \mathrm{NaCl}$. C, $\beta$ Glucuronidase (GUS) concentration (fluorimetric measurements) expressed in different tissues of transgenic potato plants in the presence of $\mathrm{NaCl}$. observed in crude nuclear extracts from galls (Fig. 3B), the complex appeared as a non-specific supershift, and all labeled probe was retarded (Fig. 5, lanes 2 and 4). Addition of a 5,000 -fold molar excess of poly (dI-dC) allowed formation of the expected, well-defined bands both in root tips and leaf extracts (Fig. 5, lanes 3 and 5). The retarded bands from noninfected tissues were indistinguishable from the retarded bands from galls. This result confirmed that a much lower DNA-binding activity than in the galls was also present in non-infected tomato tissues, and demonstrated the plant origin of the protein(s) involved in the formation of complexes with the LEMMI9 promoter.

\section{The $L E M M I 9$ binding site for gall and leaf nuclear proteins maps to a 111-bp region immediately upstream from the transcription start point.}

To narrow down the region in the LEMMI9 promoter responsible for nuclear protein binding, the XhoI-HinfI DNA fragment was digested with AseI (Fig. 2), and the two resulting segments (111 and 89 bp) were isolated, end-labeled, and used independently as probes in EMSAs. Figure 6A shows that the 111-bp fragment proximal to the transcription start point was retarded by gall nuclear proteins in the presence of poly (dI-dC) (lane 2), producing a major retarded band and a fainter one of lower mobility, suggesting the formation of a new class of complexes that were not revealed when the longer $L E M M I 9$ promoter fragment was used as a probe (see Discussion).

The 89-bp segment, which does not bind proteins from galls (Fig. 6A, lane 4) or adult non-infected tissues (data not shown) under the conditions tested in this work, contains several AT-rich stretches. AT-rich sequences are known to be associated with active chromatin in embryo- and seed-specific

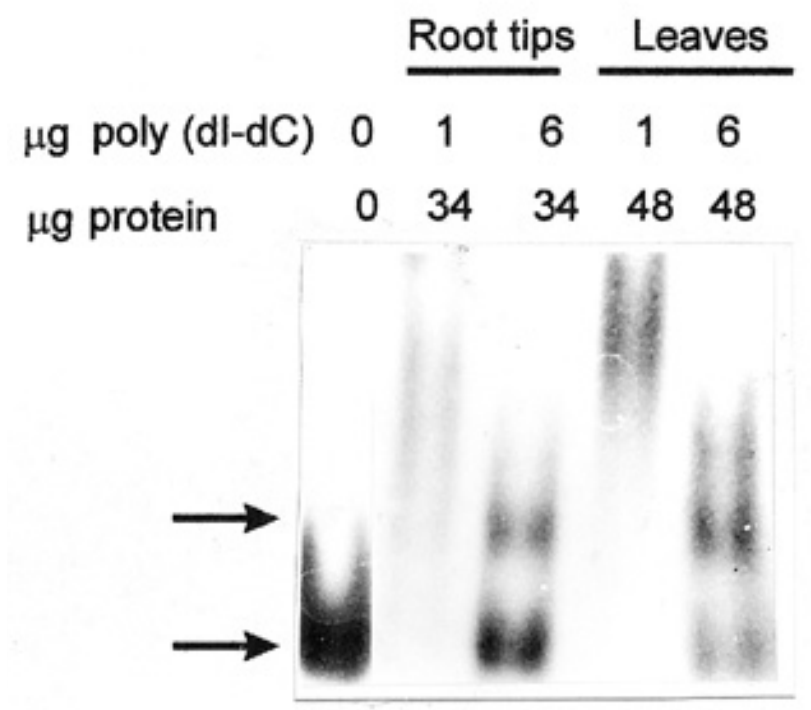

Fig. 5. DNA-binding activities of nuclear extracts from non-infected plants. Electrophoretic mobility-shift assays (EMSAs) were performed with nuclei-enriched protein extracts obtained from root tips or leaves of non-infected plants: $3 \mathrm{fmol}$ of the labeled XhoI-HinfI DNA fragment were used for all lanes. Protein and poly (dI-dC) concentrations are indicated in each lane. Positions after migration of the free probe (lower bands) and the DNA-protein complexes (retarded bands) are marked by arrows. 
promoters (Pedersen et al. 1991). To test whether such sequences in the LEMMI9 promoter might bind proteins from other actively dividing systems, different from galls, we compared the retardation patterns of both DNA fragments incubated with nuclear extracts of an embryogenic carrot cell suspension (Fig. 6B). The 89-bp fragment produced a retarded band in the presence of $6 \mu \mathrm{g}$ of poly (dI-dC) (Fig. 6B, lane 2), but it was competed away by only $3 \mu \mathrm{g}$ of poly (dA-dT) (Fig. $6 \mathrm{~B}$, lane 4), indicating the possible involvement of the AT-rich sequences in the binding activity. Conversely, the 111-bp DNA fragment that gave the specific binding with nuclear proteins from galls did not form any detectable complex when challenged with the carrot extract (Fig. 6B, lane 7). These results indicate, first, that the proteins involved in complex formation with the proximal region of LEMMI9 promoter may not be ubiquitously present in dividing cells, but are particularly abundant in galls, and, second, that several proteinbinding elements are overlaid in the proximal region of the LEMMI9 promoter but only some of them seem to be recognized in vitro by nuclear proteins from galls.

Both the crude nuclear protein extract from root galls (Fig. $6 \mathrm{C}$, lanes 2 and 3) and the enriched nuclear protein fraction from leaves (Fig. 6C, lanes 4 and 5) produced parallel retarded bands when challenged with the proximal 111-bp fragment, in the presence of a 5,000-fold excess of poly (dI-dC). This suggested the formation of similar protein-DNA complexes with the two types of extracts, although the DNA-binding activity from leaves was only revealed when nuclei-enriched extracts were used.

\section{A 12-bp element in the proximal promoter region is a candidate for the protein binding.}

A CANNTG box (CAATTG) is present in the 111-bp proximal promoter region, within a 12-bp imperfect repeat starting at position -95 and extending up to $22 \mathrm{bp}$ upstream from the putative TATA box (Fig. 2). This box is also present in promoters of genes expressed during embryogenesis and/or in vegetative tissues in response to water or high osmolarity stress (Marcotte et al. 1989; Mundy et al. 1990; Pla et al. 1993; see Discussion). To explore whether this box could be responsible for the retarded bands, oligonucleotides representing the proximal repeat and harboring the CAATTG box (5'tcgagcaCAATTGTGACCCgag and its complementary
5'tcgactcGGGTCACAATTGtgc) were synthesized, annealed to form double-stranded DNA, and used as competitor DNA in EMSAs. These specific oligonucleotides prevented the labeled LEMMI9 111-bp fragment from binding to nuclear proteins from galls (Fig. 7, compare lanes 2 to 4 with lanes 5 to 7 ), while nonspecific oligonucleotides (lane 8) or a large excess of poly (dI-dC) (lanes 9 and 10) did not affect the binding. The lower competition efficiency of the specific oligonucleotides with respect to the LEMMI9 DNA fragment (Fig. 7)
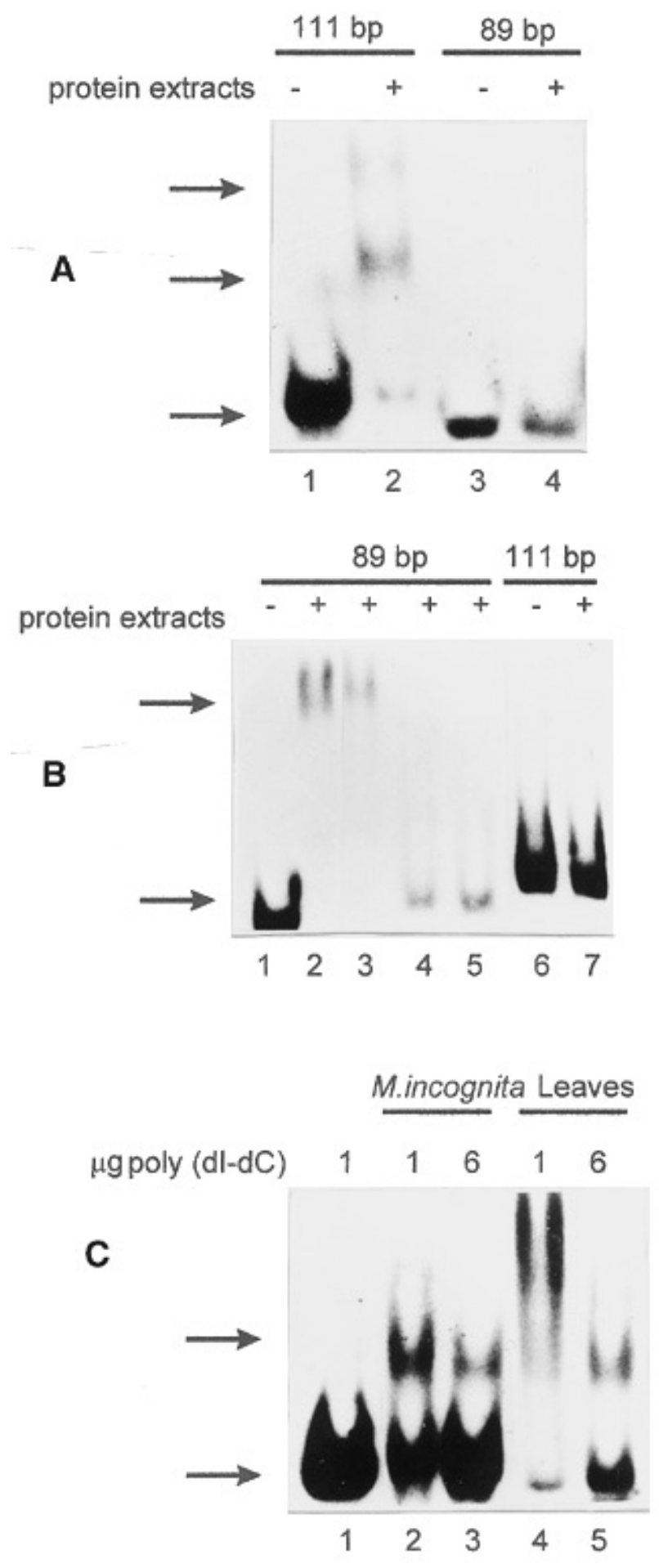

Fig. 6. Identification in the $L E M M I 9$ promoter of the region responsible for protein binding. DNA used for the electrophoretic mobility-shift assays (EMSAs), 3 fmol of the 111-bp AseI-HinfI DNA fragment (Fig. 2), or 7 fmol of the labeled 89-bp XhoI-AseI fragment, was incubated in the presence of $1 \mu \mathrm{g}$ of poly (dI-dC) unless otherwise stated. Positions after migration of the free probe (lower bands) and the DNA-protein complexes (retarded bands) are marked by arrows. A, The 89- and 111-bp DNA probes were incubated with gall crude nuclear extract ( $40 \mu \mathrm{g}$ of total protein) in the lanes indicated. B, Crude nuclear extract from a carrot cell suspension (50 $\mu \mathrm{g}$ of total protein) was incubated with the two DNA probes as indicated. As competitor DNA, $6 \mu \mathrm{g}$ of poly (dI-dC) (lane 2), or 1 (lane 3), 3 (lane 4), or $6 \mu \mathrm{g}$ (lane 5) of poly (dA-dT) was included. C, Crude nuclear protein extracts from galls $(40 \mu \mathrm{g}$ of total protein, lanes 2 and 3 ) or enriched protein extracts (50 $\mu \mathrm{g}$ of total protein, lanes 4 and 5) was used in the EMSAs with the 111-bp fragment immediately upstream from the transcription start point in the LEMMI9 promoter. Lane 1: no nuclear extract. EMSAs were performed in the presence of different amounts of poly (dI-dC) as indicated. 
could be due to their small size. This might cause a decreased stability of the DNA-protein complexes. It is also possible that the oligonucleotides could not adopt the same structure as the restriction fragment needed for optimum protein binding.

\section{DISCUSSION}

\section{Analysis of the LEMMI9 gene and promoter activation pattern.}

LEMMI9 appears to be a single gene in tomato, as judged both from the Southern data (Van der Eycken et al. 1996) and the fact that all five clones selected from the genomic library were shown to be tightly overlapping and to contain the same gene. No mismatches were found between the exon sequences of the genomic clone from cv. VFNT Cherry (resistant) and the cDNA clone from cv. Marmande (susceptible), revealing that the nucleotide sequence is conserved in both cultivars. Our data demonstrate that a gene that may be important in a compatible interaction is also present in a nematode-resistant cultivar. This fact, however, is not surprising, because of the low basal expression of LEMMI9 in many organs (Van der Eycken et al. 1996; Figs. 2 and 4), suggesting a basic function of the LEMMI9 protein in the uninfected plant.

This work shows that the LEMMI9 gene promoter from cv. VFNT Cherry can be strongly activated in giant cells of transgenic potato plants after nematode infection, in agreement with the reported accumulation of LEMMI9 transcripts in tomato giant cells (Van der Eycken et al. 1996). Our data suggest that the promoter itself might be sufficient for high levels of LEMMI9 transcription in tomato galls and no other region of the gene seems to be required. The 1,414-bp fragment immediately upstream from the start of transcription of LEMMI9 promoter was enough to confer expression in giant cells in the

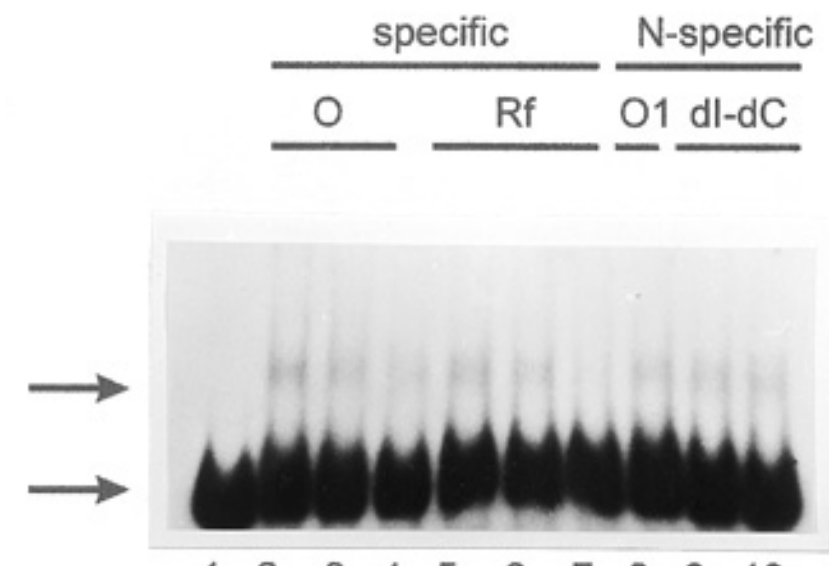

Fig. 7. Binding of nuclear proteins to a repeated motif in the proximal LEMMI9 promoter. Nuclear extracts from galls (40 $\mu \mathrm{g}$ of total protein) were incubated with $5 \mathrm{fmol}$ of the 111-bp probe in the presence of increasing amounts of unlabeled specific or non-specific competitor DNA. Lanes 2, 3, and 4: 10-, 100-, and 1,000-fold molar excess of doublestranded (ds) oligonucleotide representing the LEMMI9 element (O); lanes 5, 6, and 7: 0, 10-, and 100-fold molar excess of the 111-bp restriction fragment corresponding to the unlabeled probe (Rf); lane 8: 2,500-fold molar excess of non-specific ds oligonucleotide (O1); lanes 9 and 10: 4 and $8 \mu \mathrm{g}$ of poly (dI-dC); lane 1: no protein. All lanes except 9 and 10 included $1 \mu \mathrm{g}$ of poly $(\mathrm{dI}-\mathrm{dC})$ as non-specific competitor. Positions after migration of the free probe (lower bands) and the DNAprotein complexes (retarded bands) are marked by arrows. potato system. Thus, dissection and detailed analysis of this promoter region could give us important clues about the transcriptional regulation of LEMMI9.

\section{Putative promoter elements in LEMMI9.}

The nematode responsiveness of the LEMMI9 promoter in transgenic potato plants paralleled the expression pattern of the LEMMI9 gene in tomato. However, expression was not restricted to giant cells in either system, and both the gene (in tomato) and the promoter (in potato) were active in noninfected plants, although to a lower extent. This lack of specificity may compromise the use of the LEMMI9 promoter in engineering nematode resistance (i.e., by driving the expression of cytotoxins or antisense RNA of feeding site-induced genes). To allow the construction of modified versions of the promoter with increased specificity, we tried to identify the putative specific element(s) responsible for the LEMMI9 induction in giant cells.

We have detected a DNA-binding activity in protein extracts from tomato galls with a 200-bp fragment containing the putative TATA box and the sequences immediately upstream as a probe. The DNA-protein interaction was specific, as demonstrated by both its stability under high non-specific competitor concentration and by competition experiments with the unlabeled probe. The possibility that the retarded bands were due to interaction of the promoter with proteins of nematode origin is unlikely, since the binding activity was also detected in uninfected plants with highly enriched nuclear protein extracts from organs that showed basal expression of LEMMI9. Therefore, we propose that the retarded band(s) represent(s) specific complex(es) formed by sequences within the proximal LEMMI9 promoter with plant nuclear proteins that may be related to the transcriptional activation of the gene.

Both DNA-binding activity and transcript accumulation in tomato and promoter activation in potato were clearly detectable after 2 weeks of nematode infection and until completion of the nematode's life cycle, suggesting that the protein product encoded by LEMMI9 may play a role in the functioning of the feeding structures during most of the infection period. Based on the high sequence similarity with the cotton LEA14A protein, which is a putative ion sequestering protein accumulated during water stress, it appears that LEMMI9 could also function as an osmotic protectant. However, the cotton and tomato genes seem to have divergent expression profiles (Van der Eycken et al. 1996; Gheysen et al. 1996), as can be expected from the differences in their promoter sequences. For example, in contrast to the Leal4-A promoter, no ACGTcontaining elements were found within the LEMMI9 promoter sequence. ACGT-containing elements are involved in ABAmediated gene induction during desiccation (ABRE elements), and are present in the promoters of most ABA-regulated genes (Michel et al. 1993; Galau et al. 1993). Some genes induced under osmotic stress or during developmentally programmed desiccation can also be expressed in unstressed tissues by exogenous application of ABA (Skriver and Mundy 1990 and references in there). Consistent with the absence of the ABRE motif in the promoter is the fact that LEMMI9 showed no apparent induction upon treatment with $\mathrm{ABA}$ or upon drought stress (Van der Eycken et al. 1996), and only limited induction upon high salt stress (Fig. 4). These data suggest that generalized or systemic high osmotic pressure is not the (main) 
trigger for LEMMI9 induction, although it does not exclude a possible role in localized transient osmotic unbalances and water-potential changes at the cellular level, during which a putative ion chelator such as LEMMI9 might play a protective role. For instance, cell expansion in differentiating zones of meristems and during the growth of giant cells, or intense traffic of nutrients as in vascular tissues and in giant cells, may impose the need of osmoprotectants in very specific cell types, rather than their overall induction throughout the plant or the organ. Transcript accumulation of the salt-inducible TAS14 gene in galls of tomato roots also points toward the same direction.

The limiting amount of nuclear proteins that can be obtained from nematode-induced root galls precluded classical footprinting of the promoter. Therefore, to identify the region of the promoter engaged in complex formation, we analyzed two separate subfragments within the 200-bp promoter region. Only the 111-bp subfragment that contained the sequences immediately upstream of the transcription start point was able to form the specific protein-DNA complexes with nuclear extracts from either root galls or non-infected leaves. Both the proximal 111-bp and the more distal 89-bp DNA fragments contain AT-rich stretches, which have been described to bind nuclear proteins involved in the expression of seed-specific promoters (Thomas 1993). Nuclear proteins from embryogenic carrot cell cultures, which express a number of $L E A s$ and other seed-specific genes (Zimmerman 1993), recognized the AT-rich regions in the 89-bp fragment, but not in the 111bp region involved in complex formation with tomato gall and leaf nuclear proteins. Since the complexes formed by leaf proteins were not disturbed by high concentrations of poly $(\mathrm{dA}-\mathrm{dT})$, it seems that the specific DNA-binding activity detected in vitro with the proximal promoter region is not due to these AT-rich sequences. This finding agrees with a modular organization for the LEMMI9 promoter, and suggests that it should be possible to separate sequence elements involved in giant cell-specific expression from those controlling gene expression in other cell types.

The 111-bp fragment involved in nuclear protein binding contains a CANNTG box (CAATTG) located 22 bp upstream from the TATA box. Different versions of the CANNTG box are present in promoters of genes expressed during embryogenesis and/or in vegetative tissues in response to water or high osmotic stress (Marcotte et al. 1989; Mundy et al. 1990; Pla et al. 1993). Involvement of these CANNTG boxes in binding of nuclear proteins from galls is supported by the competition assays performed with synthetic oligonucleotides representing this element.

Although the most persistent retarded band detected in extracts from root galls and non-infected plant tissues could represent complexes with the CAATTG box, the 111-bp fragment includes a 12-bp direct imperfect repeat that harbors similar sequences (Fig. 2). A dimeric binding site is suggested by the eventual detection of another slower migrating retarded band when the 111-bp fragment is assayed with high protein concentrations (Fig. 6A). The faster migrating band, easily detected in gall extracts, could represent protein binding to either of the two repeats. When higher protein concentrations are used, simultaneous occupancy of both sites could occur, originating a subpopulation of complexes that would migrate slower, as we actually detected. Experiments aimed to demon- strate the function of these repeats in nematode inducibility of plant promoters are in progress. Recent "in vivo" footprinting experiments (J. Uribe and C. Fenoll, unpublished) suggest that both 12-bp imperfect repeats may play a role in protein binding "in vivo."

In conclusion, we have shown that the tomato LEMMI9 promoter is active and induced after nematode infection in a heterologous system. The dissection of the promoter revealed a 111-bp region that specifically binds nuclear proteins from tomato galls, where LEMMI9 is highly expressed. The motif CAATTG might be responsible for the specific binding. The identification of these discrete sequence(s) will aid in design of modified promoter-GUS fusions to test their role in the nematode responsiveness of the LEMMI9 promoter. Specific induction of LEMMI9-derived promoters in giant cells will allow the construction of nematode-resistant plants by expressing sequences for nematode control, specifically in feeding sites. Such nematode-responsive element (s) will also be useful in the identification of transcription factors involved in gene expression at feeding sites, which will give us new clues to a better understanding of the compatible plantnematode interaction.

\section{MATERIALS AND METHODS}

\section{Nematode populations.}

Two Meloidogyne incognita populations were used. One was isolated from soils in Spain and identified as M. incognita var. M5 by Alfonso Navas (CSIC, Madrid); the other one is a Race 1 population maintained in vitro on tomato hairy roots (Van der Eycken et al. 1996).

\section{Plant material.}

Two nematode-susceptible cultivars of tomato (Lycopersicon esculentum), Rutgers and Marmande, and one resistant cultivar, VFNT Cherry, were used. For EMSAs, seeds of cv. Rutgers were germinated at $26^{\circ} \mathrm{C}$ on vermiculite for 5 days, transferred to acid-washed sand supplemented with Hoagland growth solution (Hoagland and Arnon 1938), and grown under a 16-h photoperiod, and at 26 and $18^{\circ} \mathrm{C}$ as day and night temperatures. For Northern analyses, cv. Marmande seedlings were grown in hydroponic culture with $50 \%$ Hoagland medium. Plants were harvested for RNA extraction when they were in the four- to five-true-leaf stage, and after 2 days of growth in the same medium supplemented with $171 \mathrm{mM}$ $\mathrm{NaCl}$, or without added $\mathrm{NaCl}$ as controls.

Transgenic potato plants (Solanum tuberosum cv. Bintje) were obtained by Agrobacterium tumefaciens-mediated transformation. The binary vector contained $1,414 \mathrm{bp}$ from the LEMMI9 promoter immediately upstream from the ATG, fused to the coding region of the GUS gene (J. De Meutter, E. Van der Schueren, K. Van Audenhove, J. Janssens, W. Van der Eycken, M. Van Montagu, S. Ohl, and G. Gheysen, unpublished). To facilitate the cloning, an $\mathrm{NcoI}$ site was introduced at the ATG of the LEMMI9 sequence. The plants were subjected to salt stress $(171 \mathrm{mM} \mathrm{NaCl})$ during 2 days and then transferred to normal medium for another 2 days. Plants were analyzed on day 0 (before salt stress), on day 2 (during salt stress), and on day 4 (after salt stress) for GUS activity.

Embryogenic Daucus carota cell suspensions (kindly provided by Nicola Stace, John Innes Centre, UK ) were grown at 
$26^{\circ} \mathrm{C}$ in Gamborg medium supplemented with $0.5 \mathrm{mg}$ of 2,4D per liter at $80 \mathrm{rpm}$ in an Innova 4000 incubator shaker (New Brunswick Scientific, Edison, NJ).

\section{Plant inoculation and gall harvesting.}

Potato transgenic lines were grown on plates with modified Knop medium (Sijmons et al. 1991; 10 plates with three cuttings each) at $22^{\circ} \mathrm{C}$ in a day/night regime of $16 / 8 \mathrm{~h}$. After 16 days, plants were infected with 10 juveniles $(\mathrm{J} 2)$ of $M$. incognita per root tip and incubated at $28^{\circ} \mathrm{C}$ in a day/night regime of $16 / 8 \mathrm{~h}$.

For tomato gall production, eggs were obtained from stock tomato plants and hatched in distilled water at $26^{\circ} \mathrm{C}$ for 1 to 3 days. J2 were collected, counted, and immediately used for plant inoculations. At different times after infection the plants were taken out of the pots, and their roots washed and spread on an ice-cold glass plate. Individual galls were localized under a binocular microscope, removed with a scalpel, and kept at $4^{\circ} \mathrm{C}$ or frozen in liquid nitrogen for further processing. Equivalent sections from non-infected control plants were harvested in parallel for each experiment.

\section{GUS assays on transgenic potato plants.}

The histochemical GUS assay (Jefferson et al. 1987) was done daily during the first week and subsequently once a week. Fluorimetric GUS assays for salt-treated plants were performed as described by Rao and Flynn (1992).

\section{Screening of the genomic library.}

The genomic library from tomato cv. VFNT Cherry was a gift from Robert Fisher (University of California, Berkeley). The library consists of fragments obtained by a partial Sau3A digest of tomato cv. VFNT Cherry DNA cloned in the BamHI site of the replacement vector Charon 35 . We have screened this library by "in situ" hybridization of bacteriophage plaques to a $\left[\alpha-{ }^{32} \mathrm{P}\right] \mathrm{dCTP}-$ labeled $L E M M I 9$ cDNA probe according to Benton and Davis (1977). Five positive clones were purified. DNA was prepared, digested with either EcoRI or HindIII, and blotted for hybridization against specific probes. 3'- and 5 '-specific cDNA fragments were obtained by double digestion of the LEMMI9 cDNA clone in pUC19 with BamHI and HindIII. The purified fragments were used as template for the synthesis of labeled probes.

\section{Synthesis of probes.}

Plasmid DNA was prepared from the LEMMI9 cDNA clone in pUC19 with a plasmid midi kit (Qiagen, Chatsworth, CA). For DNA gel blot hybridizations, ${ }^{32} \mathrm{P}$-labeled probes were synthesized with $25 \mathrm{ng}$ of purified cDNA fragment and a Random Primed DNA Labeling Kit (Boehringer Mannheim; Lewes, UK). ${ }^{32}$ P-labeled riboprobes were synthesized for RNA blot analysis, with a LEMMI9 cDNA clone in pGem2 (Promega, Madison, WI) and the Riboprobe Gemini Core System (Promega). In both cases, excess free label was removed with Bio-Spin 30 Chromatography Columns (Bio-Rad, Hercules, CA).

For the EMSAs, promoter fragments were obtained from pLEMMI9. This is a pUC19 vector with an insertion of a 3.5$\mathrm{kb}$ EcoRI LEMMI9 genomic fragment, containing part of the first intron, the first exon with the postulated translation start point, and $3 \mathrm{~kb}$ of upstream sequence of the LEMMI9 tomato gene. A 746-bp EcoRI and XhoI fragment band from pLEMMI9 containing the proximal promoter region was digested with HinfI and electrophoresed to purify the 200-bp XhoI-HinfI fragment used for the EMSAs. End-labeling was performed by filling in with an $\mathrm{Exo}^{-}$mutant version of DNA polymerase from bacteriophage $\Phi 29$ (Esteban et al. 1992). Polymerase $\Phi 29$ was a kind gift from Margarita Salas (Centro de Biología Molecular, CSIC-UAM, Madrid). Restriction enzymes were from Boehringer Mannheim (Lewes, UK) and reactions were performed following the manufacturer's instructions.

\section{Sequence analysis.}

Based on the restriction map of the genomic clone, restriction sites were selected for sequence analysis according to Maxam and Gilbert (1977). The sequences obtained were used to synthesize primers for dideoxy sequencing. DNA sequences were further analyzed on alkaline-denatured plasmid DNA, with T7 Sequencing Mixes (Pharmacia, Uppsala, Sweden), according to the manufacturer's protocol. Genomic and cDNA sequences were aligned with GCG software (version 7.3; Genetics Computer Group, Madison, WI). The LEMMI9 genomic sequence has been deposited in the EMBL/GenBank/ DDBJ data bases under accession number Z69032.

\section{RNA gel blot analysis.}

Total RNA was extracted as described by Jones et al. (1985) and separated ( $6 \mu \mathrm{g}$ per lane) through $2.2 \mathrm{mM}$ formaldehyde agarose gels. The RNA was transferred to a Hybond-N membrane by a wet blotting procedure and fixed under UV in a Bio-Rad GS Gene Linker. After hybridization the blots were exposed to X-ray film with intensifying screens at $-70^{\circ} \mathrm{C}$.

\section{Nuclear extracts.}

Crude protein nuclear extracts were obtained by the method described by Fenoll et al. (1988) with some modifications (C. Escobar, F. Aristizábal, and C. Fenoll, unpublished). Typically, 1 to $6 \mathrm{~g}$ of freshly collected galls or control root sections was ground in a chilled mortar with $1 \mathrm{~g}$ of acid-washed sand as abrasive. All the buffers contained a protease inhibitor mixture $(0.2$ $\mathrm{mM}$ phenylmethylsulfonylfluoride [PMSF] and $0.1 \mathrm{mg}$ each of leupeptin, pepstatin A, chymostatin, antipain, and $N$-tosylL-phenylalanine chloromethyl ketone per ml, all from Sigma [St. Louis, MO]). The final crude nuclear protein extract was adjusted to $20 \%$ (vol/vol) glycerol and stored at $-70^{\circ} \mathrm{C}$.

When a more enriched nuclear protein extract was needed for non-infected tissues, a method based on Percoll gradientpurified nuclei was followed according to Giuliano et al. (1988) with some modifications (C. Escobar, F. Aristizábal, and C. Fenoll, unpublished). Nuclear proteins in the final supernatant were precipitated with ammonium sulfate, desalted by ultrafiltration, and stored at $-70^{\circ} \mathrm{C}$ in the appropriate buffer until their use.

Total protein was estimated by the Bradford procedure (Bradford 1976), with a kit from Bio-Rad.

\section{Electrophoretic mobility shift assays.}

EMSAs were performed essentially according to Fenoll et al. (1990). DNA-protein binding reactions were performed in a total volume of $20 \mu \mathrm{l}$, and contained 1 to $10 \mathrm{fmol}$ of endlabeled probe and $1 \mu \mathrm{g}$ of double-stranded poly (dI-dC) as non-specific competitor DNA (unless stated otherwise). The 
dried gels were exposed to X-ray film with intensifying screens at $-70^{\circ} \mathrm{C}$.

\section{ACKNOWLEDGMENTS}

We are indebted to Alfonso Navas (CSIC, Madrid) and Soledad Verdejo (IRTA, Cabrils) for providing the Meloidogyne incognita populations and for their generous help with the nematodes, and Nicola Stace (John Innes Centre, Norwich) for providing the carrot cell cultures. We also thank José Antonio Pintor-Toro for the TAS14 clone and Riet De Rycke for help with the sections. Part of the results shown in this paper have been reported in their preliminary stage at the 4th ISPMB Congress. The work was supported by grants BIO95-0164 from the CICyT and $\mathrm{C} 106 / 90$ from the CAM to C. F. and by grant No. 73 from the Vlaams Actieprogramma Biotechnologie of the IWT (Belgium), which also funded a predoctoral fellowship to N. B.; J. D. M. has a predoctoral fellowship of the VIB; F. A. A. was supported by a Colombian Colciencias graduate fellowship; G. G. is Senior Research Assistant of the National Fund for Scientific Research (Belgium). The collaboration between Madrid and Gent has been made possible thanks to the European Union contracts FAIR3-CT96-1714 and BIO4-CT96-0318.

\section{LITERATURE CITED}

Barthels, N., van der Lee, F. M., Klap, J., Goddijn, O. J. M., Karimi, M., Puzio, P., Grundler, F. M. W., Ohl, S. A., Lindsey, K., Robertson, L., Robertson, W. M., van Montagu, M., Gheysen, G., and Sijmons, P. C. 1997. Regulatory sequences of Arabidopsis drive reporter gene expression in nematode feeding sites. Plant Cell 9:2119-2134.

Benton, W. D., and Davis, R. W. 1977. Screening $\lambda \mathrm{gt}$ recombinant clones by hybridization to single plaques "in situ". Science 196:180-182.

Bird, D. M., and Wilson, M. A. 1994. DNA sequence and expression analysis of root-knot nematode-elicited giant cell transcripts. Mol. Plant-Microbe Interact. 7:419-424.

Bradford, M. M. 1976. A rapid and sensitive method for the quantitation of microgram quantities of protein utilizing the principle of proteindye binding. Anal. Biochem. 72:248-254.

Coca, M. A., Almoguera, C., Thomas, T. L., and Jordano, J. 1996. Differential regulation of small heat-shock genes in plants: Analysis of a water-stress-inducible and developmentally activated sunflower promoter. Plant Mol. Biol. 31:863-876.

Dure, L., III. 1993. The LEA proteins of higher plants. Pages 325-335 in: Control of Plant Gene Expression. D. P. S. Verma, ed. CRC Press, Boca Raton, FL.

Espelund, M., Saeboe-Larssen, S., Hughes, D. W., Galau, G. A., Larne, F., and Jakobsen, K. S. 1992. Late embryogenesis-abundant genes encoding proteins with different numbers of hydrophilic repeats are regulated differentially by abscisic acid and osmotic stress. Plant $\mathbf{J}$. 2:241-252.

Esteban, J. A., Bernard, A., Salas, M., and Blanco, L. 1992. Metal activation of synthetic and degradative activities of $\Phi 29$ polymerase, a model enzyme for protein-primed DNA replication. Biochemistry 31: 350-359.

Fenoll, C., Aristizábal, F. A., Sanz-Alférez, S., and Del Campo, F. F. 1997. Regulation of gene expression in feeding sites. Pages 133-149 in: Cellular and Molecular Aspects of Plant-Nematode Interactions. C. Fenoll, S. Ohl, and F. M. W. Grundler, eds. Kluwer Academic Press, Dordrecht, The Netherlands.

Fenoll, C., Black, D. M., and Howell, S. H. 1988. The intergenic region of maize streak virus contains promoter elements involved in rightward transcription of the viral genome. EMBO J. 7:1589-1596.

Fenoll, C., Schwartz, J. J., Black, D. M., Schneider, M., and Howell, S. H. 1990. The intergenic region of maize streak virus contains a GCrich element that activates rightward transcription and binds maize nuclear factors. Plant Mol. Biol. 15:865-877.

Galau, G. A., Wang, H. Y. C., and Hughes, D. W. 1993. Cotton Lea5 and Leal4 encode atypical late embryogenesis-abundant proteins. Plant Physiol. 10:695-696.

Gheysen, G., Van der Eycken, W., Barthels, N., Karimi, M., and Van Montagu, M. 1996. The exploitation of nematode-responsive plant genes in novel nematode control methods. Pestic. Sci. 47:95-101.

Giuliano, G., Pichersky, E., Malik, V. S., Timko, M. P., Scolnick, P. A., and Cashmore, A. R. 1988. An evolutionary conserved protein binding sequence upstream of a plant light-regulated gene. Proc. Natl.
Acad. Sci. USA 85:7089-7093.

Goddijn, O. J. M., Lindsey, K., van der Lee, F. M., Klap, J. C., and Sijmons, P. C. 1993. Differential gene expression in nematode-induced feeding structures of transgenic plants harboring promoter-gusA fusion constructs. Plant J. 4:863-873.

Godoy, J. A., Luna, R., Torres-Schumann, S., Moreno, J., Rodrigo, R. M., and Pintor-Toro, J. A. 1994. Expression, tissue distribution and subcellular localization of dehydrin TAS14 in salt-stressed tomato plants. Plant Mol. Biol. 26:1921-1934.

Godoy, J. A., Pardo, J. M., and Pintor-Toro, J. A. 1990. A tomato cDNA inducible by salt stress and abscisic acid: Nucleotide sequence and expression pattern. Plant Mol. Biol. 15:695-705.

Gurr, S. J., McPherson, M. J., Scollan, C., Atkinson, H. J., and Bowles, D. J. 1991. Gene expression in nematode-infected plant roots. Mol. Gen. Genet. 226:361-366.

Hoagland, D. R., and Arnon, D. I. 1938. The water culture method for growing plants without soil. Univ. Calif. Agric. Exp. Stn. Circ. 347:1-39.

Huang, C. S. 1985. Formation, anatomy and physiology of giant cells induced by root-knot nematodes. Pages 155-164 in: An Advanced Treatise on Meloidogyne. Vol. 1. J. N. Sasser and C. C. Carter, eds. North Carolina State University Graphics, Raleigh.

Jefferson, R. A., Kavanagh, T. A. and Bevan, M. W. 1987. GUS-fusions: $\beta$-Glucuronidase as a sensitive and versatile gene fusion marker in higher plants. EMBO J. 6:3901-3907.

Jones, J. D. G., Dunsmuir, P., and Bedbrook, J. 1985. High level expression of introduced chimaeric genes in regenerated transformed plants. EMBO J. 4:2411-2418

Jones, M. G. K. 1981. Host cell responses to endoparasitic nematode attack: Structure and function of giant-cells and syncytia. Ann. Appl. Biol. 97:353-372.

Marcotte, W. R., Russell, S. H., and Quatrano, R. S. 1989. Abscisic acid responsive sequences from the $E M$ gene of wheat. Plant Cell 1:969-976.

Maxam, A. M., and Gilbert, W. 1977. A new method of sequencing DNA. Proc. Natl. Acad. Sci. USA 74:560-564.

Michel, D., Salamini, F., Bartels, D., Dale, P., Baga, M., and Szalay, A. 1993. Analysis of a desiccation and ABA-responsive promoter isolated from the resurrection plant Craterostigma plantagineum. Plant J. 4:29-40.

Mundy, J., Yamaguchi-Shinozaki, K., and Chua, N.-H. 1990. Nuclear proteins bind conserved elements in the abscisic acid-responsive promoter of a rice $R A B$ gene. Proc. Natl. Acad. Sci. USA 87:1406-1410.

Opperman, C. H., Taylor, C. G., and Conkling, M. A. 1994. Root-knot nematode directed expression of a plant root-specific gene. Science 263:221-223

Pedersen, T. J., Arwood, L. J., Spiker, S., Guiltinan, M. J., and Thompson, W. F. 1991. High mobility group chromosomal proteins bind to AT-rich tracts flanking plant genes. Plant Mol. Biol. 16:95-104.

Pla, M., Vilardell, J., Guiltinan, M. J., Marcotte, W. R., Niogret, M. F., Quatrano, R. S., and Pagés, M. 1993. The cis regulatory element CCACGTGG is involved in ABA and water-stress responses of the maize gene rab28. Plant Mol. Biol. 21:259-266.

Rao, A. G., and Flynn, P. 1992. Microtiter plate-based assay for $\beta$-Dglucuronidase: A quantitative approach. Pages 89-99 in: GUS Protocols: GUS Gene as a Reporter of Gene Expression. S. R. Gallagher, ed. Academic Press, San Diego, CA.

Sasser J. N., and Carter C. C., eds. 1985. An Advanced Treatise on Meloidogyne. North Carolina State University Graphics, Raleigh.

Sijmons, P. C. 1993. Plant-nematode interactions. Plant Mol. Biol. 23: 917-931.

Sijmons, P. C., Atkinson, H. J., and Wyss, U. 1994. Parasitic strategies of root nematodes and associated host cell responses. Ann. Rev. Phytopathol. 32:235-260.

Sijmons, P. C., Grundler, F. M. W., Von Mende, N., Burrows, P. R., and Wyss, U. 1991. Arabidopsis thaliana as a new model host for plantparasitic nematodes. Plant J. 1:245-254.

Skriver, K., and Mundy, J. 1990. Gene expression in response to abscisic acid and osmotic stress. Plant Cell 2:503-512.

Thomas, T. L. 1993. Gene expression during plant embryogenesis and germination: An overview. Plant Cell 5:1401-1410.

Van der Eycken, W., Engler de Almeida, J., Inzé, D., Van Montagu, M., and Gheysen, G. 1996. A molecular study of root-knot nematodeinduced feeding sites. Plant J. 9:45-54.

Zimmerman, L. J. 1993. Somatic embryogenesis: A model for early development in higher plants. Plant Cell 5:1411-1423. 